\title{
Managing for species composition or diversity? Pastoral and free grazing systems in alkali steppes
}

\author{
Péter Török ${ }^{\mathrm{a}, *}$, Orsolya Valkó ${ }^{\mathrm{a}}$, Balázs Deák ${ }^{\mathrm{a}}$, András Kelemen ${ }^{\mathrm{a}}$, Edina Tóth ${ }^{\mathrm{b}}$, \\ Béla Tóthmérész ${ }^{\mathrm{a}}$ \\ ${ }^{a}$ MTA Biodiversity and Ecosystem Services Research Group, Debrecen, Egyetem Sqr. 1, H-4032, Hungary \\ b University of Debrecen, Department of Ecology, Debrecen, Egyetem Sqr. 1, H-4032, Hungary
}

\section{A R T I C L E I N F O}

\section{Article history:}

Received 24 August 2015

Received in revised form 7 January 2016

Accepted 8 January 2016

Available online $\mathrm{xxx}$

\section{Keywords:}

Dry grassland

Year-round grazing

Grazing intensity

Functional diversity

Grassland restoration

Plant trait

\begin{abstract}
A B S T R A C T
Free grazing and herding of local breeds have a long tradition in management and conservation of extended grassland habitats such as alkali steppes. However, there is a lack in studies evaluating the effects of grazing types and regimes on the vegetation composition and functional diversity. We selected Artemisia steppes, a widespread type of alkali steppes, to study the changes of vegetation composition and diversity along a grazing intensity gradient. We recorded the cover of vascular plant species, in altogether 150, $2 \times 2$-m-sized plots of 15 steppes in 2014. The steppes were managed by free grazing, traditional Hungarian Grey cattle grazing (low, moderate and high intensity), or by heavy grazing (Grey cattle and sheep, and additional donkey grazing). We answered the following questions: (i) How do the species richness, diversity and species evenness change along the increasing intensity of grazing? (ii) How does the grazing affect the functional trait composition along the intensity gradient? (iii) How similar is the composition and diversity of free grazed steppes to the pastoral grazed ones? We detected no significant differences in species richness but a humped-back curve with a peak at the medium grazing intensity was found for the Shannon diversity, evenness and the proportion of subordinated target species. The highest Rao's quadratic entropy was found for low intensity grazing. The lowest scores of multi-trait functional evenness were detected for the medium grazing intensity, while for multi-trait functional divergence both medium and very high intensity displayed low scores. The intensity of grazing was negatively correlated with the plant height and LDMC, while positively with the rosette forming, SLA, thousand-seed weights, terminal velocity and flowering period. Our results suggest that for the highest functional diversity a low intensity traditional cattle grazing is recommended. A medium grazing intensity should be chosen to have the highest proportion of subordinated target species of conservation interest, and the highest species diversity and evenness. Our findings suggest that free grazing and lowintensity traditional grazing can be substitutive to each other; various grazing intensities from low to medium, alternating in space and/or time can be appropriate to maintain high compositional diversity.
\end{abstract}

(c) 2016 Elsevier B.V. All rights reserved.

\section{Introduction}

A high level of biodiversity in Europe is associated to habitats maintained by low-intensity farming such as extensively managed pastures (Báldi et al., 2013; Dengler et al., 2014; Dumont et al., 2011). Multiple threats in the form of agricultural intensification, urbanisation, increased rate of afforestation together with the large-scale abandonment of low production areas caused a decline both in the area and diversity of species-rich pastures in many

\footnotetext{
* Corresponding author.

E-mail address: molinia@gmail.com (P. Török).
}

parts of the continent (Henle et al., 2008). The poorly or inappropriately adapted measures within the agri-enviromental schemes, especially in Central- and Eastern European countries, are usually not eligible to mitigate these negative changes (Sutcliffe et al., 2015). Nature conservation authorities are seeking for cost-effective and proper solutions for the management of pastures to ensure both economic sustainability and biodiversity conservation.

Grazing by cattle is less selective for forbs and sustains a higher vegetation compared to sheep or horse grazing (Jerrentrup et al., 2015). Cattle grazing provides high patchiness and heterogeneity in vegetation, which is beneficial for the conservation of species richness and habitat mosaics (Metera et al., 2010). The effect of 
cattle grazing is highly dependent on the type of grazer, duration of grazing, vegetation type and it is influenced by the grazing intensity (Schaich et al., 2010; Török et al., 2014). Traditional herding of local cattle breeds and free grazing are both considered as promising tools to achieve conservation goals in Europe. In nature conservation and grassland management local robust cattle breeds are considered as suitable livestock (Mann and Tischew, 2010; Gilhaus et al., 2014; Török et al., 2014).

Hungarian Grey cattle, which is a traditional beef cattle in the Carpathian Basin, was domesticated in the 13th century and thereafter became an important export good of the Kingdom of Hungary. After the Second World War during the collectivisation in the socialist regime the breed almost completely disappeared (Bartosiewicz, 1997). In the past decades Hungarian Grey cattle became increasingly used in conservation and management of various grassland types including alkali steppes, which are traditionally maintained by grazing (Török et al., 2014). However, case studies on grazing effects of robust cattle breeds on pasture vegetation are rather scarce (but see Mann and Tischew, 2010; Török et al., 2014; Gilhaus et al., 2014; Cornelissen and Vulink, 2015).

Beyond the analysis of the specific changes in cover and taxonomic diversity a more functional approach became increasingly involved in analyzing the usefulness of biodiversity conservation and restoration measures (Teuber et al., 2013; Kechang et al., 2015; Komac et al., 2015). A trait-based approach by studying the various components of functional diversity may reveal mechanisms how management influences both biodiversity and related ecosystem functioning (Carmona et al., 2012). To have a reliable and complex view of management related changes in vegetation a joint analysis of taxonomic diversity and functional diversity is necessary (Peco et al., 2012). In this study we compared the species- and trait composition of Artemisia steppes along a grazing intensity gradient. We specifically answered the following questions: (i) How do the species richness, diversity and species evenness change along the increasing intensity of grazing? (ii) How does the grazing affect the functional trait composition along the intensity gradient? (iii) How similar is the composition and diversity of free grazed steppes to the pastoral grazed ones?

\section{Material and methods}

Alkali steppes are low production grasslands traditionally managed by extensive cattle and sheep grazing. Alkali steppes are of special interest in the Natura 2000 network included as a priority habitat type: "Pannonic salt steppes and salt marshes (1530)". Alkali steppes are one of the best preserved grassland habitats in Europe, typical for the Pannonian biogeographical region, having the largest and best preserved stands in Hungary (Eliáš et al., 2013; Török et al., 2011). They harbour several plant and animal species listed in Annex I and Annex II of the Habitats Directive, such as Cirsium brachycephalum or Gortyna borelii lunata.

We studied the vegetation of Artemisia steppes, a widespread type of alkali steppes along a grazing intensity gradient. Artemisia steppes are generally used as pastures and are characterised by the high abundance of a short-growing bunchgrass Festuca pseudovina (typically up to a cover of 70\%, Kelemen et al., 2015). Artemisia steppes are moist in springtime and become completely dry in early summer; in some cases polygonal cracks occur on the soil surface. The soil is characterised by a moderate alkaline $\mathrm{pH}$, medium to high soil water capacity, low organic matter content, and low to medium salt content (mostly $\mathrm{Na}_{2} \mathrm{CO}_{3}$ and $\mathrm{K}_{2} \mathrm{CO}_{3}$ ) in the upper soil layer (for more details see Valkó et al., 2014). Characteristic subordinated species are Artemisia santonicum, Podospermum canum, Trifolium angulatum, Achillea setacea and Achillea collina, Lotus tenuis, Cerastium dubium, Bupleurum tenuissimum, Gypsophila muralis, Limonium gmelinii subsp. hungarica. In intensively grazed stands short-lived species like Hordeum hystrix, Bromus mollis, Matricaria chamomilla, Polygonum aviculare can be frequent (Török et al., 2011).

The studied steppes are in the Hortobágy National Park near to the villages Hortobágy, Egyek, Balmazújváros, Tiszafüred, Püspökladány and Kunmadaras within a radius of $35 \mathrm{~km}$. The climate of the region is moderately continental, characterised by a mean annual temperature of $9.5^{\circ} \mathrm{C}$ and a mean annual precipitation of $550 \mathrm{~mm}$. The yearly maximum of precipitation can be detected generally in June (a mean of $80 \mathrm{~mm}$ ) characterised by high year-toyear fluctuations (Lukács et al., 2015).

We selected altogether 12 steppes managed either by free grazing ( 3 steppes, year-round grazing by Heck cattle, 0.1 animal unit/ha), or traditional herding of Hungarian Grey cattle grazing (cattle herds grazed the steppes from early April to late days of November, in low, moderate and high intensity: $0.5,1.5$, and 2.5 animal unit/ha, respectively, 3 steppes each). There were also 3 overgrazed steppes selected ( 4 animal unit/ha, Grey cattle and sheep, occasionally donkey grazing). We recorded the cover of vascular plant species, total cover of mosses and lichens (later pooled as cryptogams) in ten, $2 \times 2$-m-sized plots evenly distributed on a typical 1-ha-large area in each steppe in late May 2014 (altogether 150 plots).

For the trait based analyses we obtained data from Király (2009) for the followings: (i) combined trait for life span and forbgraminoid status (short-lived forb-perennial forb, short-lived graminoid, perennial graminoid), (ii) start of flowering and (iii) total flowering period, (iv) canopy structure (rosette forming or no rosettes), and (v) average plant height. Data was obtained from CLO-PLA database for lateral clonal spreading ability (Klimešová and de Bello, 2009); species were classified into four simplified categories based on potential distance of clonal spreading (m/year): (1) no clonal spreading, (2) <0.01 m/year, (3) 0.01-0.25 m/year, and (4) >0.25 m/year (Kelemen et al., 2015). Leaf traits (Leaf dry matter content-LDMC, Leaf dry weight, Specific leaf area-SLA, Leaf area-LA) were obtained from LEDA trait base (Kleyer et al., 2008). The dataset were completed by own measurements using standardised measurement protocols (Cornelissen et al., 2003). For the seed weights locally compiled own measurements were available (published data in Török et al., 2013, 2016). Data for terminal velocity, were obtained from LEDA (Kleyer et al., 2008) or D3 databases (Hintze et al., 2013). Species of conservation interest (characteristic species of Artemisia steppes referred as target species hereafter) were selected using Török et al. (2012) and Kelemen et al. (2013) and refined by the personal expertise of the authors.

We calculated community weighted means (CWM) and functional divergence for each single trait. For the continuous scale quantitative trait data (average height, LDMC, Leaf dry weight, SLA, LA, Seed weights, and terminal velocity) we calculated multi-trait based indices: Rao's quadratic entropy (Q), functional richness (FRic), functional divergence (FDiv), and functional evenness (FEve) (Mouchet et al., 2010; Pla et al., 2012). For weighting we used Euclidean distances of the species matrix. We also calculated species richness, Shannon diversity and evenness scores for each plot. For the calculation of all of the indices we used FDiversity program package (Casanoves et al., 2011). We compared both the vegetation and functional characteristics of steppes with different grazing intensity using univariate GLMs and Tukey-test, where 'grazing intensity' was included as fixed factor and 'steppe' as random weighting factor. The GLMs were calculated using SPSS 17.0 program package. To analyse the relationship between community weighted means of respective traits and grazing intensity we used a PCA (validating crucial factors) and CCA. To analyse the significance of the CCA a Monte-Carlo permutation test 
(full model) was applied using the default 499 random permutations in CANOCO 4.5 (Lepš and Šmilauer, 2003). To visualise the compositional differences in vegetation we used an NMDS with Bray-Curtis similarity calculated by $\mathrm{R}$ (version 3.2.0).
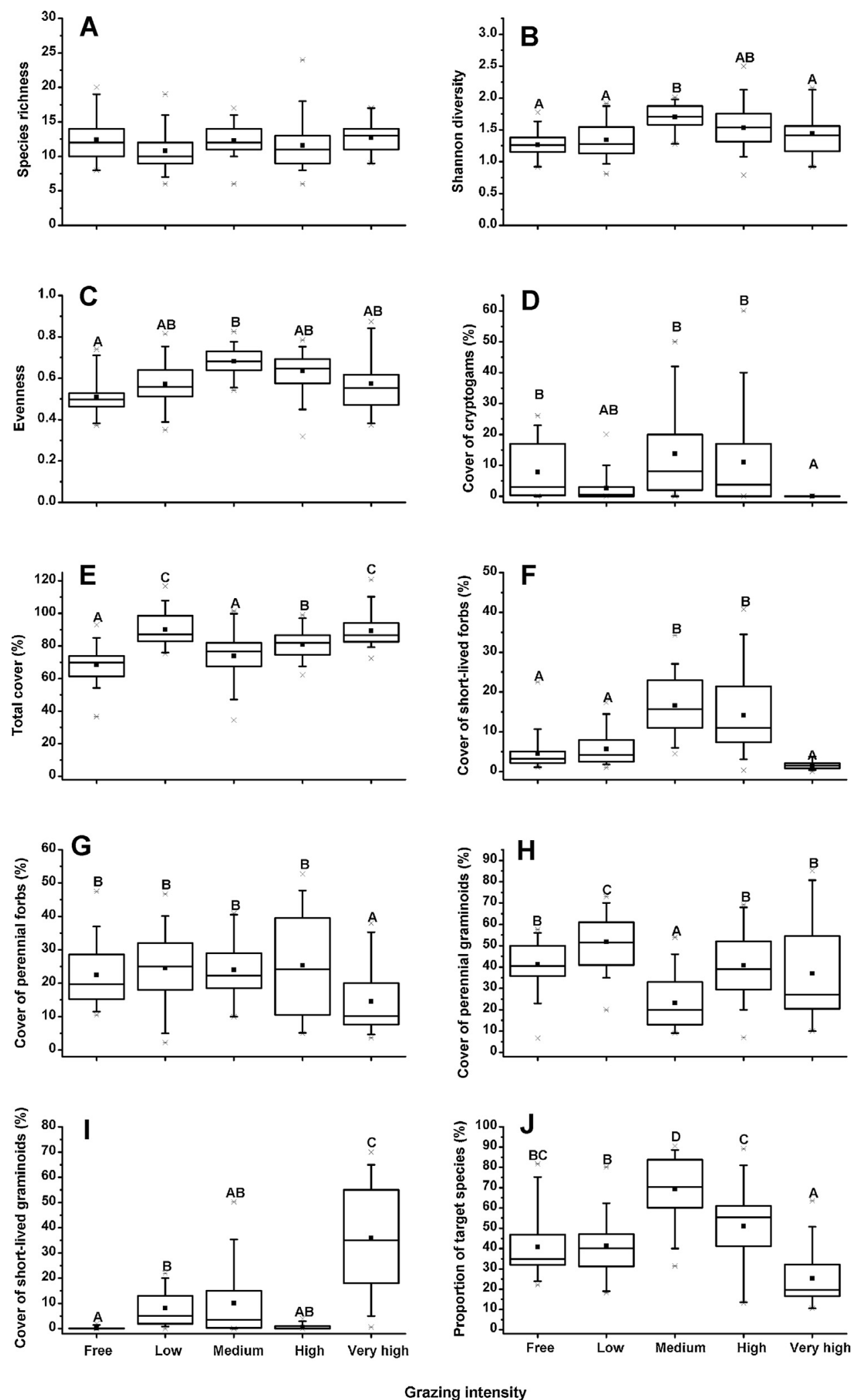

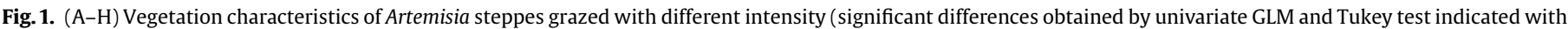

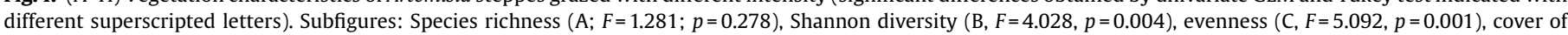

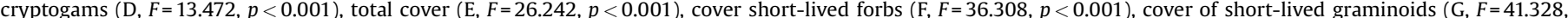

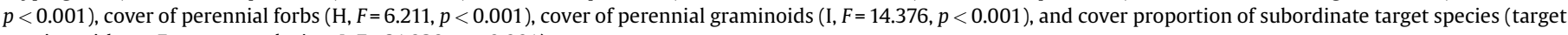
species without Festuca pseudovina, J, F=31.929, $p<0.001$ ). 


\section{Results}

\subsection{Vegetation characteristics}

We found altogether 82 species in the 15 steppes. There were 22 perennial forb species, 13 perennial graminoids, 40 short-lived forbs, and 7 species of short-lived graminoids. We detected no significant difference in species richness between steppes managed with different intensity of grazing (Fig. 1A). We detected a hump-shaped curve for Shannon diversity and evenness along the increasing gradient of grazing intensity. Thus, the highest scores for both figures were detected in the steppes with medium grazing intensity (Fig. 1B and C), while the lowest score for evenness was found in free grazed steppes. We detected an increasing trend of total vegetation cover with increasing grazing intensity in exception of the low intensity grazed steppes. This increase was in accordance with the increase of total short-lived cover (Fig. 1E-H). The vegetation composition of steppes managed by high intensity grazing was quite different from that of the other steppes displayed clearly by the NMDS ordination (Fig. 2). This was mainly due to the high cover of salt-tolerant species such as Puccinellia limosa, Spergularia media, L. tenuis and by the very high cover of the short-lived graminoid Hordeum hystrix. In case of the other steppes no such clear separation was detected, however, the plot-by-plot variability expressed in the size of point clouds increased with the increase of grazing intensity. The cover of cryptogams was the lowest in the steppes managed with very high grazing intensity (Fig. 1D). The proportion of subordinated target species (species characteristic to the studied grasslands excluding the dominant grass $F$. pseudovina) showed a very marked humped-back relationship with the grazing intensity having a peak at the medium intensity (Fig. 1J).

\subsection{Trait composition}

We detected no significant difference in functional richness between steppes managed with increasing intensity of grazing (Table 1). The highest scores of Rao's quadratic entropy were found in case of low intensity grazing, and a continuous decrease of scores were detected from low to very high grazing intensity (Table 1 ), except for steppes managed by free grazing. Considering the multi-trait functional evenness the lowest scores were detected for the medium grazing intensity, while for multi-trait functional divergence both medium and very high intensity displayed the low scores.

Based on the results of GLM the individual functional divergence indices displayed a rather complex response to grazing intensity, but most of the divergence scores showed a humpedback relationship with a peak detected in steppes managed with low to high grazing intensity (Table 1 ). We included grazing intensity and the weighted means of the studied 11 traits in a multivariate analysis. We selected the traits with high correlations $(|R|>0.5 \mid)$ with one of the first three species axes by a PCA. The validated traits were specific plant height $(-0.739)$, LDMC $(-0.792)$, likeliness of rosette forming (0.797), SLA (0.928), thousand-seed weights (0.691), terminal velocity (0.574) and flowering period (0.706). The validated traits were included into a canonical correspondence analysis (CCA). The eigenvalues for the first and second axis were 0.677 and 0.208 , respectively. The detected pattern in the CCA was significantly different from the random pattern (Monte-Carlo permutation test, number of permutations were $499, F=45.76, p=0.002$ for the first and $F=20.18, p=0.002$ for all canonical axes). We found that the intensity of grazing was negatively correlated with the plant height and the LDMC, while positively with the likeliness of rosette forming, SLA, thousand-seed weights, terminal velocity and

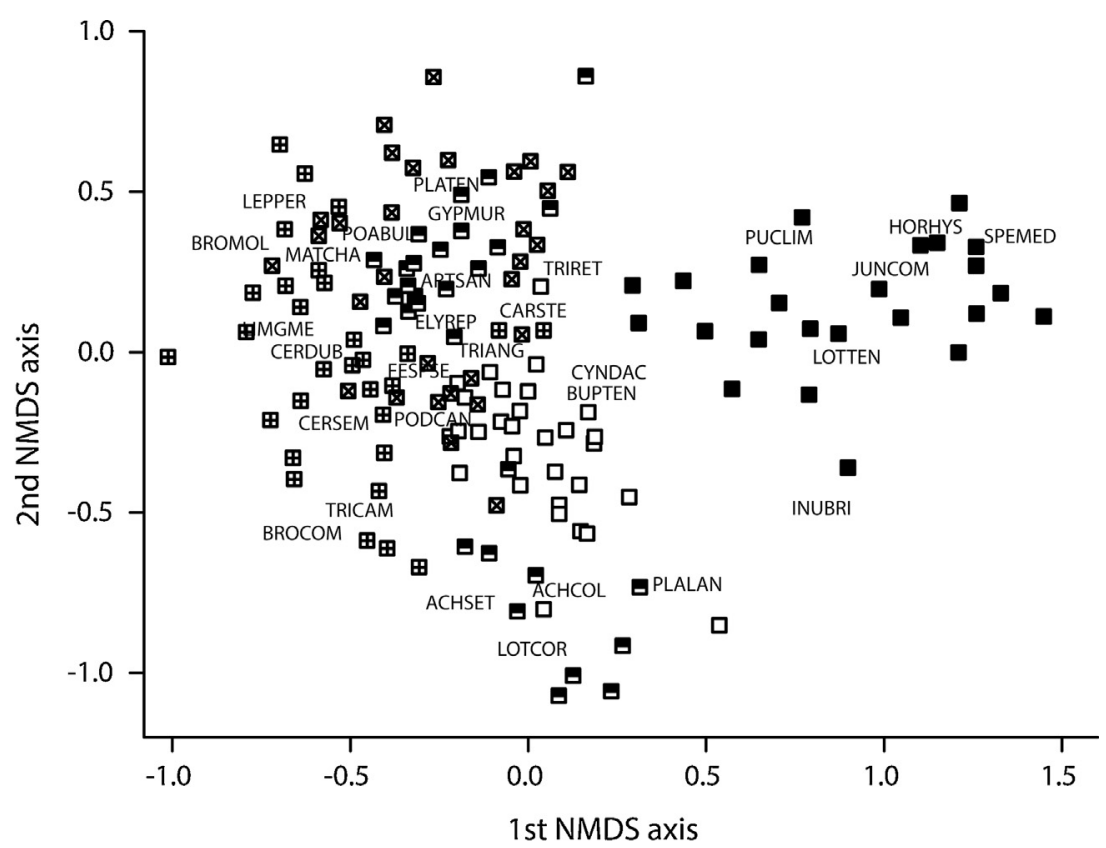

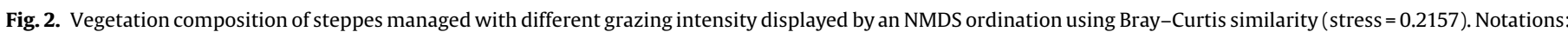

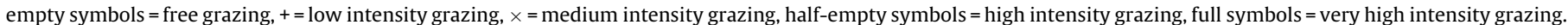

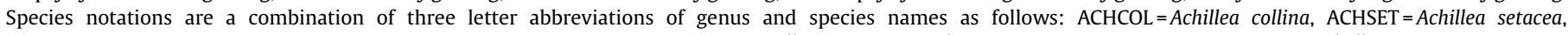

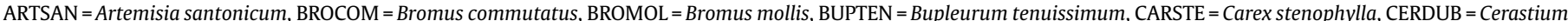

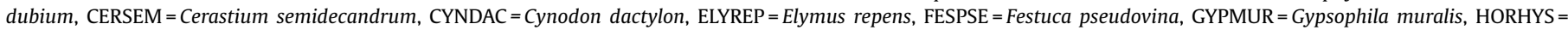

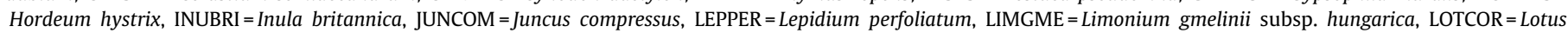

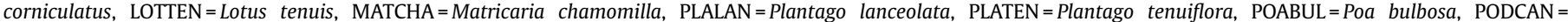

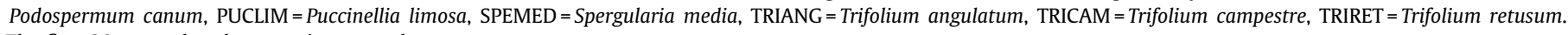
The first 30 most abundant species were shown. 
Table 1

The functional trait characteristics of Artemisia steppes with different gazing intensity (mean, significant effect of intensity was denoted by boldface).

\begin{tabular}{|c|c|c|c|c|c|c|c|}
\hline & \multicolumn{2}{|c|}{ Effect of intensity } & \multicolumn{5}{|c|}{ Grazing intensity levels } \\
\hline & $F$ & $p$ & $\begin{array}{l}\text { Free } \\
0.1 \mathrm{AU} / \mathrm{ha}\end{array}$ & $\begin{array}{l}\text { Low } \\
0.5 \mathrm{AU} / \mathrm{ha}\end{array}$ & $\begin{array}{l}\text { Medium } \\
1.5 \mathrm{AU} / \mathrm{ha}\end{array}$ & $\begin{array}{l}\text { High } \\
2.5 \mathrm{AU} / \mathrm{ha}\end{array}$ & $\begin{array}{l}\text { Very high } \\
4 \mathrm{AU} / \mathrm{ha}\end{array}$ \\
\hline \multicolumn{8}{|l|}{ Multitrait indices $^{\mathrm{d}}$} \\
\hline Rao $\left(\times 10^{4}\right)$ & 5.812 & $<\mathbf{0 . 0 0 1}$ & $10.90^{\mathrm{A}}$ & $86.82^{\mathrm{B}}$ & $56.42^{\mathrm{AB}}$ & $49.05^{\mathrm{AB}}$ & $17.88^{\mathrm{A}}$ \\
\hline Functional richness $\left(\times 10^{8}\right)$ & 1.452 & 0.220 & 3.08 & 18.17 & 13.47 & 12.89 & 2.04 \\
\hline Functional evenness & 4.983 & 0.001 & $0.39^{\mathrm{AB}}$ & $0.31^{\mathrm{AB}}$ & $0.25^{\mathrm{A}}$ & $0.39^{\mathrm{B}}$ & $0.38^{\mathrm{B}}$ \\
\hline Functional divergence & 5.304 & 0.001 & $0.61^{\mathrm{AB}}$ & $0.61^{\mathrm{AB}}$ & $0.54^{\mathrm{A}}$ & $0.72^{\mathrm{B}}$ & $0.55^{\mathrm{A}}$ \\
\hline \multicolumn{8}{|l|}{ Single trait indices } \\
\hline \multicolumn{8}{|l|}{ Community Weighted mean } \\
\hline Specific plant height & 24.74 & $<0.001$ & $35.72^{\mathrm{BC}}$ & $38.03^{\mathrm{C}}$ & $32.60^{\mathrm{B}}$ & $36.04^{\mathrm{C}}$ & $27.64^{\mathrm{A}}$ \\
\hline Start of flowering & 13.988 & $<\mathbf{0 . 0 0 1}$ & $5.48^{\mathrm{AB}}$ & $5.44^{\mathrm{A}}$ & $5.72^{\mathrm{B}}$ & $5.62^{\mathrm{B}}$ & $5.29^{\mathrm{A}}$ \\
\hline Flowering period & 6.616 & $<\mathbf{0 . 0 0 1}$ & $2.80^{\mathrm{AB}}$ & $2.73^{\mathrm{A}}$ & $3.00^{\mathrm{AB}}$ & $3.15^{\mathrm{B}}$ & $3.18^{\mathrm{B}}$ \\
\hline Clonal spread & 13.567 & $<\mathbf{0 . 0 0 1}$ & $2.24^{\mathrm{AB}}$ & $2.18^{\mathrm{AB}}$ & $2.01^{\mathrm{A}}$ & $2.38^{\mathrm{B}}$ & $1.97^{\mathrm{A}}$ \\
\hline Rosette formation likeliness & 22.556 & $<\mathbf{0 . 0 0 1}$ & $0.20^{\mathrm{A}}$ & $0.22^{\mathrm{A}}$ & $0.23^{\mathrm{A}}$ & $0.19^{\mathrm{A}}$ & $0.53^{\mathrm{B}}$ \\
\hline Leaf dry weight & 6.873 & $<\mathbf{0 . 0 0 1}$ & $9.50^{\mathrm{A}}$ & $46.17^{\mathrm{B}}$ & $28.32^{\mathrm{AB}}$ & $19.31^{\mathrm{A}}$ & $12.83^{\mathrm{A}}$ \\
\hline LDMC & 5.328 & $<\mathbf{0 . 0 0 1}$ & $264.47^{\mathrm{AB}}$ & $263.91^{\mathrm{B}}$ & $236.74^{\mathrm{A}}$ & $247.27^{\mathrm{AB}}$ & $232.35^{\mathrm{A}}$ \\
\hline SLA & 40.861 & $<\mathbf{0 . 0 0 1}$ & $14.72^{\mathrm{A}}$ & $15.39^{\mathrm{A}}$ & $17.05^{\mathrm{A}}$ & $15.86^{\mathrm{A}}$ & $25.60^{\mathrm{B}}$ \\
\hline LA & 3.102 & 0.017 & $149.53^{\mathrm{A}}$ & $337.50^{\mathrm{A}}$ & $237.77^{\mathrm{A}}$ & $391.67^{\mathrm{B}}$ & $353.51^{\mathrm{AB}}$ \\
\hline Seed weight & 15.187 & $<\mathbf{0 . 0 0 1}$ & $0.72^{\mathrm{A}}$ & $0.81^{\mathrm{A}}$ & $0.75^{\mathrm{A}}$ & $0.87^{\mathrm{A}}$ & $1.78^{\mathrm{B}}$ \\
\hline Terminal velocity & 11.275 & $<0.001$ & $1.83^{\mathrm{A}}$ & $1.85^{\mathrm{A}}$ & $2.02^{\mathrm{AB}}$ & $2.17^{\mathrm{B}}$ & $2.24^{\mathrm{B}}$ \\
\hline \multicolumn{8}{|l|}{ Functional divergence $^{\mathrm{d}}$} \\
\hline Specific plant height & 38.303 & $<\mathbf{0 . 0 0 1}$ & $0.19^{\mathrm{A}}$ & $0.19^{\mathrm{A}}$ & $0.45^{\mathrm{B}}$ & $0.46^{\mathrm{B}}$ & $0.19^{\mathrm{A}}$ \\
\hline Leaf dry weight & 11.201 & $<\mathbf{0 . 0 0 1}$ & $0.75^{\mathrm{AB}}$ & $0.86^{\mathrm{B}}$ & $0.87^{\mathrm{B}}$ & $0.88^{\mathrm{B}}$ & $0.71^{\mathrm{A}}$ \\
\hline LDMC & 13.442 & $<\mathbf{0 . 0 0 1}$ & $0.19^{\mathrm{A}}$ & $0.36^{\mathrm{B}}$ & $0.29^{\mathrm{B}}$ & $0.21^{\mathrm{A}}$ & $0.16^{\mathrm{A}}$ \\
\hline SLA & 49.412 & $<0.001$ & $0.22^{\mathrm{AB}}$ & $0.31^{\mathrm{B}}$ & $0.26^{\mathrm{AB}}$ & $0.20^{\mathrm{A}}$ & $0.48^{\mathrm{C}}$ \\
\hline LA & 1.94 & 0.107 & 0.80 & 0.84 & 0.88 & 0.88 & 0.86 \\
\hline Seed weight & 4.02 & 0.004 & $0.88^{\mathrm{AB}}$ & $0.87^{\mathrm{A}}$ & $0.93^{\mathrm{B}}$ & $0.91^{\mathrm{AB}}$ & $0.93^{\mathrm{B}}$ \\
\hline Terminal velocity & 5.914 & $<\mathbf{0 . 0 0 1}$ & $0.33^{\mathrm{AB}}$ & $0.21^{\mathrm{A}}$ & $0.37^{\mathrm{B}}$ & $0.41^{\mathrm{B}}$ & $0.41^{\mathrm{B}}$ \\
\hline
\end{tabular}

Univariate GLM and Tukey tests; different letters in superscript indicate significant differences.

${ }^{\mathrm{d}}$ Calculated only for the continuous scale quantitative traits (see listed at single trait functional divergence).

flowering period (Fig. 3). The start of flowering was neither positively nor negatively correlated with the grazing intensity. These trends were also mostly supported by the individual GLMs of respective traits (Table 1 ).

\section{Discussion}

\subsection{Vegetation characteristics}

Most studies on grazing found that low-intensity extensive grazing generally increases, while high-intensity grazing usually decreases species richness (Fischer and Wipf, 2002; Metera et al., 2010). In contrast we found that grazing intensity did not influence species richness. The likely explanation for this that alkali steppes are generally species poor and they harbour a quite uniform species composition; thus, not the species pool, but likely the proportions of species are affected by grazing. This assumption is supported (i) by the NMDS ordination; we found a marked difference in species composition only in case of very high grazing intensity. For the other intensities we found an overlapping composition (Fig. 2). The changes in cover proportions are also supported (ii) by the detected humped-back curve for Shannon diversity and evenness with a peak at the medium grazing intensity. These findings are well in accordance with the theory of intermediate disturbance, which assumes that the highest diversity is expected if the disturbance intensity is at an intermediate level (Connel, 1978).

We found an increasing total cover mostly due to the increase in cover of short-lived species. This finding is somewhat in contrast with the study of Díaz et al. (2006), where based on a global metaanalysis of grazing effect on the vegetation, they found that in dry ecosystems with a long evolutionary history of herbivory (such as our studied steppes) no significant effect of grazing on short-lived species was detected. However, Díaz et al. (2006) did not consider neither the identity of grazing animals nor the grazing intensity (only compared grazed and ungrazed treatments), which both can

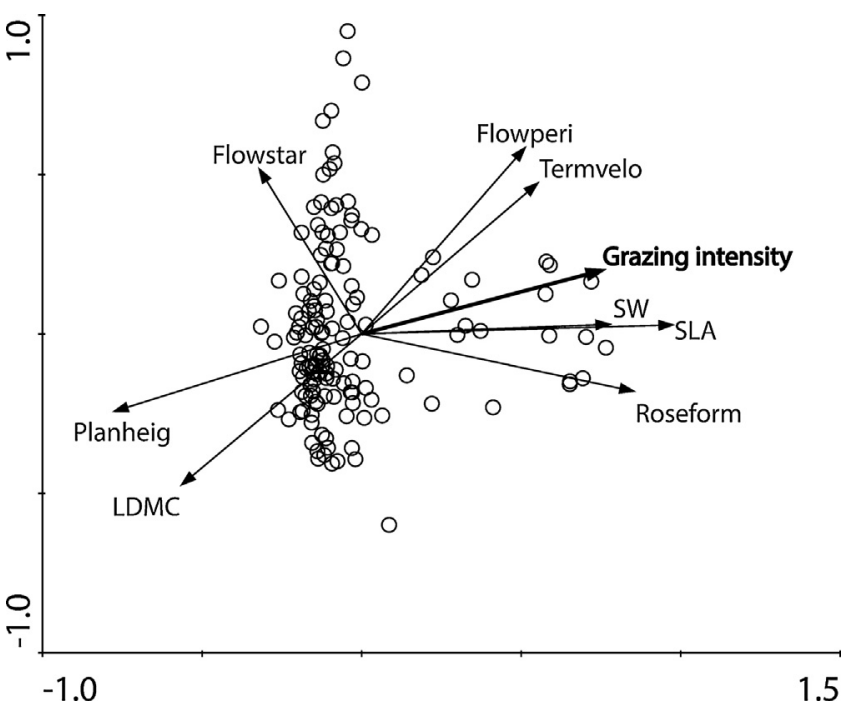

Fig. 3. The relationship of grazing intensity and measured traits (out of the analysed 11 traits, the community weighted means of 8 traits with the highest correlation with the first three species axes were selected) displayed by a CCA calculated on species cover data. Abbreviations: Flowstar $=$ start of flowering, flowperi $=$ length of flowering, termvelo=terminal velocity of seeds, intensity=grazing intensity, $\mathrm{SW}=$ thousand-seed weights, SLA $=$ specific leaf area, roseform $=$ likeliness of rosette-forming, LDMC = leaf dry matter content, planheig = plant height. Cumulative percentage variance of species-environment relation for the first four axes was 78.0, eigenvalues were for the first and second axis 0.677 and 0.208 , respectively. Monte-Carlo permutation test was significant (number permutations: 499, for the first axis: $p=0.002, F=45.76$, for all canonical axes: $p=0.002, F=20.182$ ). 
strongly influence the effect of grazing on species composition and diversity of grasslands (WallisDeVries et al., 1998). In case of domestic grazers there are marked differences between the grazing habit and grazing effects on vegetation; this is quite obvious: for example between cattle and sheep (both very widespread grazers in dry grasslands of Northern- and CentralEurope and in the Mediterranean region-Peco et al., 2006; Metera et al., 2010). Jerrentrup et al. (2015) found that sheep grazing decreases the cover of forbs in a higher magnitude compared to cattle grazing because the selective grazing of sheep (Dumont et al., 2011). In our study the high increase in the cover of shortlived species with grazing intensity can be explained by (i) selective foraging for other species (species like H. hystrix is grazed by livestock only in springtime because of its spiny spikelets), (ii) suppression of perennial species and increase in vegetation gaps (Díaz et al., 2006) (iii) increased nutrient load by grazing animals (Bullock and Pakeman, 1997) favours both disturbance- and nutrient-demanding short-lived ruderals, (iv) grazing favours mostly short-lived halophyte species (found in Loucougaray et al., 2004; and also in the present study expressed by the high cover of salt tolerant short-lived species-e.g., S. media and $H$. hystrix). It should be also noted that the additional sheep grazing could be responsible for the low cover of short-lived and perennial forbs at the very high grazing intensity, because sheep is generally much more selective for forbs (Jerrentrup et al., 2015).

\subsection{Trait composition}

We found that the intensity of grazing correlated positively with the likeliness of rosette forming, with SLA, thousand-seed weights, terminal velocity, flowering period, while negatively with the plant height and with the LDMC (Fig. 3). For leaf size traits it was formerly found that both LA and leaf dry weights were decreasing with increasing grazing pressure (Díaz et al., 2001). In our study we found that in case of weighted means of leaf dry weight there was a humped-back relationship, while that of LA tended to increase towards the high grazing intensities. However, for the compositional changes in the multivariate analysis none of these traits were proven as important predictors (Fig. 3). This contradiction to former findings can be explained by that compared to the leaf sizes the likeliness of rosette forming was much more important, and increased with the grazing intensity (see also de Bello et al., 2006). The likely explanation is that the bite of cattle is regularly high-i.e. rosette forming species are benefitted by increased intensity of cattle grazing (Jerrentrup et al., 2015).

In most of the studies it was found that plant height was negatively correlated with grazing intensity (Díaz et al., 2001; Klimešová et al., 2008; Zheng et al., 2011), which was also validated in the present study for the very high grazing intensity. However, the effect of grazing on SLA was reported to be much more complicated. Vesk et al. (2004) reported referring to Westoby (1999) that the effect of grazing on SLA is intensity dependent. This means that in case of low intensity grazing the grazing animals are likely selective for species with thin and soft leaves (high SLA), while in high grazing pressures the selectivity of grazing (because of the limited high quality food sources) decreases and both species with high and low SLA are consumed. Species with high SLA have also the benefit of faster re-growth; thus, the weighted mean of SLA increases (Vesk et al., 2004). These assumptions were also validated by our study. In addition to this we also found that the LDMC showed an opposite trend, it was rather decreasing by increasing SLA and grazing intensity (see Fig. 3; Golodets et al., 2009; Cruz et al., 2010). These results jointly validated the decreasing selectivity of cattle grazing with increasing grazing intensity.
It was reported by de Bello et al. (2005) that flowering period as an explanatory variable for grazing is much more relevant in dry conditions than in wet conditions. This finding was also corroborated in our study. We found that the increasing intensity of grazing generally favours species with longer flowering period in dry Artemisia steppes (Fig. 3, Table 1). It was formerly reported that in dense vegetation seed weights decrease with increasing grazing intensity because the recruitment by seeds is rather limited by limited space for establishment (Westoby, 1999). It was also stressed that these assumptions are not likely valid in semiarid or arid communities with relatively open canopy, where establishment is more likely limited by abiotic factors (e.g. rainfall) than by spatial constrains like limited availability of safe sites (Vesk et al., 2004). The latter assumption was supported by our findings. The increase in weighted means and also functional divergence of seed weights and terminal velocity in our study can be explained by the increase of short-lived and some perennial graminoids. It was proven that the short-lived graminoids possess the highest, while perennial graminoids the lowest seed weights in the regional flora (Török et al., 2013). Thus, the increase in weighted mean of seed weights can be explained by the high increase in short-lived graminoids (mostly $H$. hystrix) and the increase of divergence by the increase of both short-lived and perennial graminoids especially in steppes managed by high grazing intensity (in the latter group the increase of Juncus compressus, see Fig. 2).

We found the lowest functional divergence and evenness in the steppes managed by medium grazing intensity. This result is in contradiction with that of species diversity and evenness measures where the highest scores were found for the medium intensity. Functional evenness is regularly low in communities where some sections of the niche space are occupied but underutilised, which will result in a lower production. In general, low functional divergence indicates a low degree of niche differentiation and high resource competition on the cost of efficient resource use and effective ecosystem functioning (Mason et al., 2005). However, it is also suggested by de Bello et al. (2006) that traditional measurements of species diversity did not show the same pattern as the functional components of biodiversity (Rao's quadratic entropy, functional evenness and divergence). It was also stressed in the mentioned study well in accordance with our findings that an increase in species diversity is not necessarily followed by the increase of functional diversity measures. The species-traits pool concept of Díaz and Cabido (2001) and de Bello et al. (2006) also suggest that environmental filtering by stress may limit the variability in functional characteristics, which can be responsible for the detected opposite trends. Higher species richness with lower functional diversity means also a fine-scale partitioning of the available niche space, which enables a coexistence of a set of species with quite similar functional characteristics (Díaz and Cabido, 2001). Based on the above findings our results clearly suggests, in line with Peco et al. (2012), that the effect of grazing cannot be properly evaluated solely either by classical diversity measures or by plant trait based approach.

\subsection{Intensity, grazing animal and grazing type}

The aim of the present paper was to disentangle the effects of grazing intensity on the composition of steppe vegetation and functional diversity. We found that grazing intensity has remarkable effect on the vegetation and functional characteristics of the studied steppes. However, the studied steppes at the two endpoints of the intensity gradient - free grazed and very intensely grazed ones - differed not only in grazing intensity but also in grazing type (free grazing vs. herding), and in grazing animal from the steppes grazed by Hungarian Grey cattle in low to high intensity. It was reported by several studies that the effect of 
grazing on grassland diversity can be strongly influenced by the type of grazing animal (see for example Rook et al., 2004; Metera et al., 2010 or Jerrentrup et al., 2015). Thus, in our study the additional sheep grazing selective for forbs can be responsible for the low proportion of forbs in steppes managed by high grazing intensity. However, to our knowledge there were no published evidences (i) in comparison of grazing effects of different cattle types or (ii) in comparing the effect of free grazing with traditional herding. These topics are not yet addressed by the present study, but would be very important for further research.

In many places of Europe traditional herding or free low intensity grazing is suggested for the conservation and management of grassland biodiversity. In our study we found that managing for the highest species diversity or the highest functional diversity in Artemisia steppes different grazing intensities should be applied. For the highest functional diversity low intensity traditional cattle grazing is suggested, but if we would like to have the highest cover proportion of subordinated target species, the highest diversity and evenness a medium grazing intensity should be chosen.

\section{Conclusions}

Our results suggested that for maintaining high cover of grassland specialists, low intensity grazing management would be necessary. A quite similar vegetation composition with high cover of grassland specialists was detected in steppe stands managed by free grazing and low-intensity traditional grazing. This means that these measures can be substitutive to each other in managing Artemisia steppes. We also found that the species composition in exception of the steppes managed by very high grazing intensity was very similar for the other four grazing intensity categories. This means that the resistance of this community type regarding the species composition is very high, which is very important for management and conservation. However, our results clearly suggest that even for the management of such species-poor communities like Artemisia steppes, fine tuned case studies are necessary to achieve local conservation goals. Our results also suggest that very high grazing intensity and/or simultaneous grazing of animals with different grazing strategy should be avoided, since it decreases the proportion of target species. Based on the results we can suggest that the application of various grazing intensities alternating in space and/or time can be the best way to maintain high cover of target species, and high species diversity of short grass steppes and likely for other species-poor low production grasslands.

\section{Acknowledgements}

PT was supported by OTKA PD 100192 during the preparation of the manuscript. The personal support of the National Excellence Program (PT, OV, AK) are greatly acknowledged. OV was supported by OTKA PD 111807 grant. The study was supported by the SROP4.2.2.B-15/1/KONV2015-0001 project. This research was also supported by the TÁMOP $4.2 .1 / \mathrm{B}-09 / 1 / \mathrm{KONV}-2010-0007$, and TÁMOP 4.2.2/B-10/1-2010-0024 projects European Union and the State of Hungary, co-financed by the European Social Fund.

\section{References}

Báldi, A., Batáry, P., Kleijn, D., 2013. Effects of grazing and biogeographic regions on grassland biodiversity in Hungary-analysing assemblages of 1200 species. Agric. Ecosyst. Environ. 166, 28-34.

Bartosiewicz, L., 1997. The Hungarian grey cattle: a traditional European breed. Anim. Genet. Resour. Inform. 21, 49-60.

Bullock, J., Pakeman, R., 1997. Grazing of lowland heath in England: management methods and their effects on heathland vegetation. Biol. Conserv. 79, 1-13.
Carmona, C.P., Azcárate, F.M., de Bello, F., Ollero, H.S., Lepš, J., Peco, B., 2012. Taxonomical and functional diversity turnover in Mediterranean grasslands: interactions between grazing, habitat type and rainfall. J. Appl. Ecol. 49, 10841093.

Casanoves, F., Pla, L., Di Rienzo, J.A., Díaz, S., 2011. FDiversity: a software package for the integrated analysis of functional diversity. Methods Ecol. Evol. 2, 233-237. Connel, J.H., 1978. Diversity in tropical rain forests and coral reefs. Science 199, 1302-1310.

Cornelissen, J.H.C., Lavorel, S., Garnier, E., Diaz, S., Buchmann, N., Gurvich, D.E., Reich, P.B., ter Steege, H., Morgan, H.D., van der Heijden, M.G.A., Pausas, J.G., Poorter, H., 2003. A handbook of protocols for standardised and easy measurement of plant functional traits worldwide. Aust. J. Bot. 51, 335-380.

Cornelissen, P., Vulink, J.T., 2015. Density-dependent diet selection and body condition of cattle and horses in heterogeneous landscapes. Appl. Anim. Behav. Sci. 163, 28-38.

Cruz, P., De Quadros, F.L.F., Theau, J.P., Frizzo, A., Jouany, C., Duru, M., Carvalho, P.C.F., 2010. Leaf traits as functional descriptors of the intensity of continuous grazing in native grasslands in the south of Brazil. Rangeland Ecol. Manag. 63, 350-358.

de Bello, F., Lepš, J., Sebastià, M.-T., 2005. Predictive value of plant traits to grazing along a climatic gradient in the Mediterranean. J. Appl. Ecol. 42, 824-833.

de Bello, F., Lepš, J., Sebastià, M.-T., 2006. Variations in species and functional plant diversity along climatic and grazing gradients. Ecography 29, 801-810.

Dengler, J., Janišová, M., Török, P., Wellstein, C., 2014. Biodiversity of palaearctic grasslands: a synthesis. Agric. Ecosyst. Environ. 182, 1-14.

Díaz, S., Lavorel, S., McIntyre, S., Falczuk, V., Casanoves, F., Milchunas, D.G., Skarpe, C., Rusch, G., Sternberg, M., Noy-Meir, I., Landsberg, J., Zhang, W., Clark, H., Campbell, B.D., 2006. Plant trait responses to grazing - a global synthesis. Glob. Change Biol. 12, 1-29.

Díaz, S., Cabido, M., 2001. Vive la différence: plant functional diversity matters to ecosystem processes. Trends Ecol. Evol. 16, 646-655.

Díaz, S., Noy-Meir, I., Cabido, M., 2001. Can grazing response of herbaceous plants be predicted from simple vegetative traits? J. Appl. Ecol. 38, 497-508.

Dumont, B., Carrère, P., Ginane, C., Faruggia, A., Lanore, L., Tardif, A., Decuq, F., Darsonville, O., Louault, F., 2011. Plant-herbivore interactions affect the initial direction of community changes in an ecosystem manipulation experiment. Basic Appl. Ecol. 12, 187-194.

Eliáš Jr., P., Sopotlieva, D., Dítě, D., Hájková, P., Apostolova, I., Senko, D., Melečková, Z., Hájek, M., 2013. Vegetation diversity of salt-rich grasslands in Southeast Europe. Appl. Veg. Sci. 16, 521-537.

Fischer, M., Wipf, S., 2002. Effect of low-intensity grazing on the species-rich vegetation of traditionally mown subalpine meadows. Biol. Conserv. 104, 1-11.

Gilhaus, K., Stelzner, F., Hölzel, N., 2014. Cattle foraging habits shape vegetation patterns of alluvial year-round grazing systems. Plant Ecol. 215, 169-179.

Golodets, C., Sternberg, M., Kiegel, J., 2009. A community-level test of the leafheight-seed ecology strategy scheme in relation to grazing conditions. J. Veg. Sci. 20, 392-402.

Henle, K., Alard, D., Clitherow, J., Cobb, P., Firbank, L., Kull, T., McCracken, D., Moritz, R.F., Niemelä, J., Rebane, M., Wascher, D., Watt, A., Young, J., 2008. Identifying and managing the conflicts between agriculture and biodiversity conservation in Europe - a review. Agric. Ecosyst. Environ. 124, 60-71.

Hintze, C., Heydel, F., Hoppe, C., Cunze, S., König, A., Tackenberg, O., 2013. D3: the dispersal and diaspore database - baseline data and statistics on seed dispersal - perspect. Plant Ecol. Evol. Syst. 15, 180-192.

Jerrentrup, J.S., Seither, M., Petersen, U., Isselstein, J., 2015. Little grazer species effect on the vegetation in a rotational grazing system. Agric. Ecosyst. Environ. 202, 243-250.

Kechang, N., He, J.-H., Zhang, S., Lechowicz, M.J., 2015. Grazing increases functional richness but not functional divergence in Tibetan alpine meadow plant communities. Biodivers. Conserv. doi:http://dx.doi.org/10.1007/s10531-0150960-2.

Kelemen, A., Török, P., Valkó, O., Miglécz, T., Tóthmérész, B., 2013. Mechanisms shaping plant biomass and species richness: plant strategies and litter effect in alkali and loess grasslands. J. Veg. Sci. 24, 1195-1203.

Kelemen, A., Török, P., Valkó, O., Deák, B., Tóth, K., Tóthmérész, B., 2015. Both facilitation and limiting similarity shape the species coexistence in dry alkali grasslands. Ecol. Complex. 21, 34-38.

Király, G., 2009. Új Magyar Füvészkönyv. Magyarország hajtásos növényei. Határozókulcsok (New Hungarian Herbal. The Vascular Plants of Hungary. Identification Keys. Aggtelek National Park Directorate, Jósvafö.

Kleyer, M., Bekker, R.M., Knevel, I.C., Bakker, J.P., Thompson, K., Sonnenschein, M., Poschlod, P., Van Groenendael, J.M., Klimeš, L., Klimešová, J., Klotz, S., Rusch, G. M., Hermy, M., Adriaens, D., Boedeltje, G., Bossuyt, B., Dannemann, A., Endels, P., Götzenberger, L., Hodgson, J.G., Jackel, A.-K., Kühn, I., Kunzmann, D., Ozinga, W. A., Römermann, C., Stadler, M., Schlegelmilch, J., Steendam, H.J., Tackenberg, O., Wilmann, B., Cornelissen, J.H.C., Eriksson, O., Garnier, E., Peco, B., 2008. The LEDA Traitbase: a database of life-history traits of Northwest European flora. J. Ecol. 96, 1266-1274.

Klimešová, J., Latzel, V., de Bello, F., Groenendael, J.M., 2008. Plant functional traits in studies of vegetation changes in response to grazing and mowing: towards a use of more specific traits. Preslia 80, 245-253.

Klimešová, J., de Bello, F., 2009. CLO-PLA: the database of clonal and bud bank traits of Central European flora. J. Veg. Sci. 20, 511-516.

Komac, B., Pladevall, C., Domènech, M., Fanlo, R., 2015. Functional diversity and grazing intensity in sub-alpine and alpine grasslands in Andorra. Appl. Veg. Sci. $18,75-85$. 
Lepš, J., Šmilauer, P., 2003. Multivariate Analysis of Ecological Data using CANOCO. Cambridge University Press, Cambridge.

Loucougaray, G., Bonis, A., Bouzillé, J.B., 2004. Effects of grazing by horses and/or cattle on the diversity of coastal grasslands in western France. Biol. Conserv.116, 59-71.

Lukács, B.A., Török, P., Kelemen, A., Várbíró, G., Radócz, S., Takács, S., Miglécz, T., Tóthmérész, B., Valkó, O., 2015. Rainfall fluctuations and vegetation patterns in alkali grasslands-self-organizing maps in vegetation analysis. Tuexenia 35 , 381-397.

Mann, S., Tischew, S., 2010. Role of megaherbivores in restoration of species-rich grasslands on former arable land in floodplains. Waldökologie, Landschaftsforschung Naturschutz 10, 7-15.

Mason, N.W.H., Mouillot, D., Lee, W.G., Wilson, J.B., 2005. Functional richness, functional evenness and functional divergence: the primary components of functional diversity. Oikos 111, 112-118.

Metera, E., Sakowski, T., Słoniewski, K., Romanowicz, B., 2010. Grazing as a tool to maintain biodiversity of grassland - a review. Anim. Sci. Pap. Rep. 28, 315-334.

Mouchet, M.A., Villéger, S., Mason, N.W.H., Muillot, D., 2010. Functional diversity measures: an overview of their redundancy and their ability to discriminate community assembly rules. Funct. Ecol. 24, 867-876.

Peco, B., Sánchez, A.M., Azcárate, F.M., 2006. Abandonment in grazing systems: consequences for vegetation and soil. Agric. Ecosyst. Environ. 113 284-294.

Peco, B., Carmona, C.P., de Pablos, I., Azcárate, F.M., 2012. Effects of grazing abandonment on functional and taxonomic diversity of Mediterranean grasslands. Agric. Ecosyst. Environ. 152, 27-32.

Pla, L., Casanoves, F., Di Rienzo, J., 2012. Quantifying Functional Biodiversity. Springer, Dordrecht.

Rook, A.J., Dumont, B., Isselstein, J., Osoro, K., WallisdeVries, M.F., Parente, G., Mills, J., 2004. Matching type of livestock to desired biodiversity outcomes in pastures - a review. Biol. Conserv. 119, 137-150.

Schaich, H., Szabó, I., Kaphegyi, T.A.M., 2010. Grazing with Galloway cattle for floodplain restoration in the Syr Valley, Luxembourg. J. Nat. Conserv. 18, 268277.

Sutcliffe, L.M.E., Batáry, P., Kormann, U., Báldi, A., Dicks, L.V., Herzon, I., Kleijn, D. Tryjanowski, P., Apostolova, I., Arlettaz, R., Aunins, A., Aviron, A., Baležentiene, L. Čierna-Plassmann, M., Fischer, C., Gabrielová, J., Halada, L., Hartel, T., Helm, A., Hristov, I., Jelaska, S.D., Kaligarič, M., Kamp, J., Klimek, S., Koorberg, P., KovácsHostyánszki, A., Kuemmerle, T., Leuschner, C., Lindborg, R., Loos, J., Maccherini, S., Marja, R., Máthé, O., Proença, V., Rey-Benayas, J., Sans, F.X., Seifert, C., Stalenga, J., Timaeus, J., Török, P., van Swaay, C., Viik, E., Tscharntke, T., 2015.
Harnessing the biodiversity value of Central and Eastern European farmland. Divers. Distrib. 21, 722-730.

Teuber, L.M., Hölzel, N., Fraser, L.H., 2013. Livestock grazing in intermountain depressional wetlands-effects on plant strategies, soil characteristics and biomass. Agric. Ecosyst. Environ. 175, 21-28.

Török, P., Kapocsi, I., Deák, B., 2011. Conservation and management of alkali grassland biodiversity in Central-Europe. In: Zhang, W.J. (Ed.), Grasslands: Types, Biodiversity and Impacts. Nova Science Publishers Inc., New York, pp. 109-118.

Török, P., Miglécz, T., Valkó, O., Kelemen, A., Deák, B., Lengyel, Sz., Tóthmérész, B. 2012. Recovery of native grass biodiversity by sowing on former croplands: is weed suppression a feasible goal for grassland restoration? J. Nat. Conserv. 20, 41-48.

Török, P., Miglécz, T., Valkó, O., Tóth, K., Kelemen, A., Albert, Á., Matus, G., Molnár, V. A., Ruprecht, E., Papp, L., Deák, B., Horváth, O., Takács, A., Hüse, B., Tóthmérész, B., 2013. Seed weights support social behaviour types-analysis and new thousand seed weight records of the Pannonian flora. Acta Bot. Hung. 55, 429472.

Török, P., Tóth, E., Tóth, K., Valkó, O., Deák, B., Kelbert, B., Bálint, P., Radócz Sz, Kelemen, A., Sonkoly, J., Miglécz, T., Matus, G., Takács, A., Molnár, V.A., Süveges, K., Papp, L., Papp jr, L., Tóth, Z., Baktay, B., Málnási Csizmadia, G., Oláh, I., Peti, E. Schellenberger, J., Szalkovszki, O., Kiss, R., Tóthmérész, B., 2016. New measurements of thousand-seed weights of species in the Pannonian Flora. Acta Bot. Hung. 58 (1-2) (in press).

Török, P. Valkó, O., Deák, B., Kelemen, A., Tóthmérész, B., 2014. Traditional cattle grazing in a mosaic alkali landscape: effects on grassland biodiversity along a moisture gradient. PLoS One 9 Paper e97095.

Valkó, O., Tóthmérész, B., Kelemen, A., Simon, E., Miglécz, T., Lukács, B.A., Török, P. 2014. Environmental factors driving vegetation and seed bank diversity in alkali grasslands. Agric. Ecosyst. Environ. 182, 80-87.

Vesk, P.A., Leishman, M.R., Westoby, M., 2004. Simple traits do not predict grazing response in Australian dry shrublands and woodlands. J. Appl. Ecol. 41, 22-31.

WallisDeVries, M.F., Bakker, J.P., van Wieren, S.E. (Eds.), 1998. Grazing and Conservation Management. Kluwer Academic Publishers, Dordrecht.

Westoby, M., 1999. The LHS strategy scheme in relation to grazing and fire. Eldrige, D., Freudenberger, D. (Eds.), VIth International Rangeland Congress, vol. $2893-$ 896.

Zheng, S., Lan, Z., Li, W., Shao, R., Shan, Y., Wan, H., Taube, F., Bai, Y., 2011. Differential responses of plant functional trait to grazing between two contrasting dominant C3 and C4 species in a typical steppe of inner Mongolia, China. Plant Soil 340, 141-155. 